Check for updates

Cite this: Mater. Adv., 2021, 2, 4000

Received 2nd March 2021 Accepted 13th April 2021

DOI: $10.1039 / \mathrm{d} 1 \mathrm{ma} 00181 \mathrm{~g}$

rsc.li/materials-advances

\title{
A 9-fluorenyl substitution strategy for aromatic-imide-based TADF emitters towards efficient and stable sky blue OLEDs with nearly $30 \%$ external quantum efficiency $\dagger$
}

\author{
Quanyou Feng, (D) ${ }^{a}$ Xiaojun Zheng, ${ }^{a}$ Hongjian Wang, ${ }^{a}$ He Zhang, ${ }^{a}$ Yue Qian, ${ }^{a}$ \\ Kesheng Tan, ${ }^{a}$ Hongtao Cao, ${ }^{* a}$ Linghai Xie (D) *a and Wei Huang ${ }^{\text {ab }}$
}

\begin{abstract}
Highly efficient and stable blue organic lighting-emitting diodes (OLEDs) continue to be a challenge. The substitution strategy has been proven to be one of the most effective chemical approaches to improve the electroluminescence (EL) performance and the operational stability of blue OLEDs based on thermally activated delay fluorescent (TADF) emitters. Herein, the effects of tert-butyl and 9-phenyl-9fluorenyl substituents on the physicochemical properties and EL performance are systematically studied for aromatic-imide-based TADF molecules. The robust 9-phenyl-9-fluorenyl units outperform the tertbutyl groups in improving the thermal and electrochemical stability. Consequently, sky blue OLEDs based on 4-DPFCzAIAd containing 9-phenyl-9-fluorenyl substituents exhibit excellent comprehensive EL performance with a maximum external quantum efficiency of $28.2 \%$ and a long LT50 (time to $50 \%$ of initial luminance) of $178 \mathrm{~h}$ at an initial luminance of $500 \mathrm{~cd} \mathrm{~m}^{-2}$, which is much better than that of the device with a tert-butyl substituted emitter. These results demonstrate that the 9-phenyl-9-fluorenyl substituent is superior to the tert-butyl group in constructing TADF emitters for efficient and stable blue OLEDs.
\end{abstract}

\section{Introduction}

As a new generation of flat panel displays and solid state lighting technology, organic lighting-emitting diodes (OLEDs) have already been intensively studied for more than three decades since the milestone report by Tang and VanSlyke. ${ }^{1,2}$ Recently, purely organic thermally activated delay fluorescent (TADF) materials have attracted remarkable attention due to their $100 \%$ internal quantum efficiency (IQE) without the aid of noble metal atoms. ${ }^{3,4}$ This near unity IQE can be achieved by exploiting triplet excitons via efficient reverse intersystem crossing (RISC), in which a necessary small energy gap $\left(\Delta E_{\mathrm{ST}}\right)$ between the lowest singlet $\left(\mathrm{S}_{1}\right)$ and triplet $\left(\mathrm{T}_{1}\right)$ states is required. ${ }^{5-7} \mathrm{~A}$ small $\Delta E_{\mathrm{ST}}$ that can be controlled by the twisted

\footnotetext{
${ }^{a}$ State Key Laboratory of Organic Electronics and Information Displays, Institute of Advanced Materials (IAM), Nanjing University of Posts \& Telecommunications, 9 Wenyuan Road, Nanjing 210023, China. E-mail: iamhtcao@njupt.edu.cn, iamlhxie@njupt.edu.cn

${ }^{b}$ Frontiers Science Center for Flexible Electronics (FSCFE), MIIT Key Laboratory of Flexible Electronics (KLoFE), Northwestern Polytechnical University,

127 West Youyi Road, Xi'an 710072, China

$\dagger$ Electronic supplementary information (ESI) available. CCDC 2023151, 2022595 and 2023153. For ESI and crystallographic data in CIF or other electronic format see DOI: $10.1039 / \mathrm{d} 1 \mathrm{ma} 00181 \mathrm{~g}$
}

donor (D) and acceptor (A) moieties of TADF molecules is beneficial to triplet excitons up-conversion to $\mathrm{S}_{1}$ states. ${ }^{8}$ The effective separation between the highest occupied molecular orbital (HOMO) and the lowest unoccupied molecular orbital (LUMO) can be garnered by the structural distortion of D/A., ${ }^{9,10}$ Up to now, numerous metal-free TADF molecules have been explored for high efficiency blue, green and red electroluminescence (EL) with a maximum external quantum efficiency $\left(\mathrm{EQE}_{\max }\right)$ over $38 \%,{ }^{11} 37 \%{ }^{12}$ and $27 \%,{ }^{13}$ respectively.

Despite the outstanding EQE values, blue OLEDs tend to show much poorer device stability than the green and red ones owing to the higher energy level and longer excited-state lifetime. ${ }^{14,15}$ Although the device lifetime is a key parameter for further commercialization of OLEDs, it is often not collected or mentioned in various literature studies. ${ }^{16}$ To address the inherent instability of blue TADF OLEDs, the substitution strategy has been widely utilized and proven to be one of the most effective approaches. Duan and co-workers developed efficient and stable blue TADF emitters by introducing tertbutyl substituents as steric shields, which not only enhanced the photoluminescence efficiency, but also improved the stability of the TADF molecules. ${ }^{17}$ Consequently, an $\mathrm{EQE}_{\max }$ of $21 \%$ and a record LT50 (time to $50 \%$ of initial luminance) of $770 \mathrm{~h}$ at an initial luminance of $500 \mathrm{~cd} \mathrm{~m}^{-2}$ were achieved in the 
5TCzBN device without scaring the color purity. In addition, the $\pi$-conjugated substituents at the donor segments were also adopted to adjust the excited-state energy levels. Adachi et al. ${ }^{18}$ introduced phenyl groups into the carbazole donor endowing a second type of donor unit for the initial D-A system. As a result, an increased RISC rate and hence improved device efficiency as well as prolonged device lifetime were successfully realized owing to the reduced energy gap between the triplet state $\left({ }^{3} \mathrm{CT}\right)$ and localized triplet state $\left({ }^{3} \mathrm{LE}\right)$. Furthermore, we have recently presented the Friedel-Crafts arylmethylation strategy of TADF molecules to improve the EL efficiency and operational stability for deep-blue EL devices. Upon introduction of $\pi$-conjugation-interrupted substituents, 9-phenyl-9-fluorenyl units, the obtained compound DPFCz-TRZ reached a smaller singlettriplet splitting and more excellent thermal and electrochemical stability. Compared with the control device, almost the threefold EQE value and twofold device lifespan were simultaneously achieved for the DPFCz-TRZ-based deep-blue OLEDs with a similar CIE coordinate of $(0.15,0.10) .{ }^{19}$

Given that a slight change in the chemical structure of a fluorophore may significantly affect its physiochemical properties and hence the EL performance, delicate molecular engineering of TADF luminophores is crucial to achieve highly efficient and stable blue TADF OLEDs. In this work, we designed and synthesized three TADF molecules with a carbazole-based donor and phthalimide-based acceptor. 4-TBCzAIAd and 4-DPFCzAIAd were obtained by attaching tert-butyl and phenyl-9-fluorenyl groups to the 3- and 6positons of the carbazole moiety from the control compound 4-CzAIAd, respectively. The influences of these substituents were characterized by thermogravimetric analysis (TGA), differential scanning calorimetry (DSC), ultraviolet-visible (UV-vis) spectroscopy, photoluminescence (PL) and cyclic voltammetry (CV). Furthermore, the effects of tert-butyl and phenyl-9-fluorenyl groups on the EL performance including the operational lifetime of TADF-OLEDs were also systematically investigated.

\section{Results and discussion}

\section{Molecular design}

First of all, carbazole and its derivatives have been considered as one of the most efficient electron donors for constructing the blue TADF emitters. Besides, the aromatic imide-based semiconductors have been intensively investigated for their applications in organic optoelectronics due to the outstanding photoelectric properties and strong electron-withdrawing ability. ${ }^{20-25}$ However, aromatic imide-based blue TADF emitters have been rarely reported; ${ }^{26,27}$ therefore, a rational molecular design is fairly important for the purpose of preparing efficient stable aromatic-imide-based blue TADF luminophores. Considering all of these in perspective, we herein propose a 9-fluorenyl substitution strategy for constructing phthalimide-based blue TADF molecules with a carbazole unit as the electron donor. For the carbazole donor, tert-butyl and 9-phenyl-9-fluorenyl substituents are adopted with the aim to adjust the triplet energy levels, ${ }^{28}$ electron-transporting ability, ${ }^{29}$ and electrochemical and thermal stability. ${ }^{28}$ On the other hand, the rigid structure of the adamantyl group attached to the phthalimide acceptor not only leads to blue-shift emission due to the suppression of the $\pi$-conjugation effect, ${ }^{30}$ but also suppresses the Stokes shift. ${ }^{31}$ As shown in Scheme 1, the combination of the aforementioned donor, acceptor and substituents formed three TADF emitters, namely 4-CzAIAd, 4-TBCzAIAd and 4-DPFCzAIAd.

\section{Theoretical calculations}

As one of the most popular theoretical method, B3LYP hybrid functional is suitable and being used for the molecular optimization and energy calculation of TADF emitters. ${ }^{32-35}$ Herein, time-dependent density functional theory (TD-DFT) calculations at the B3LYP/6-31G(d) level were performed to investigate the influence of tert-butyl and 9-phenyl-9-fluorenyl groups on the geometrical properties and energy levels for these phthalimide-based emitters. As shown in Fig. 1, for all three

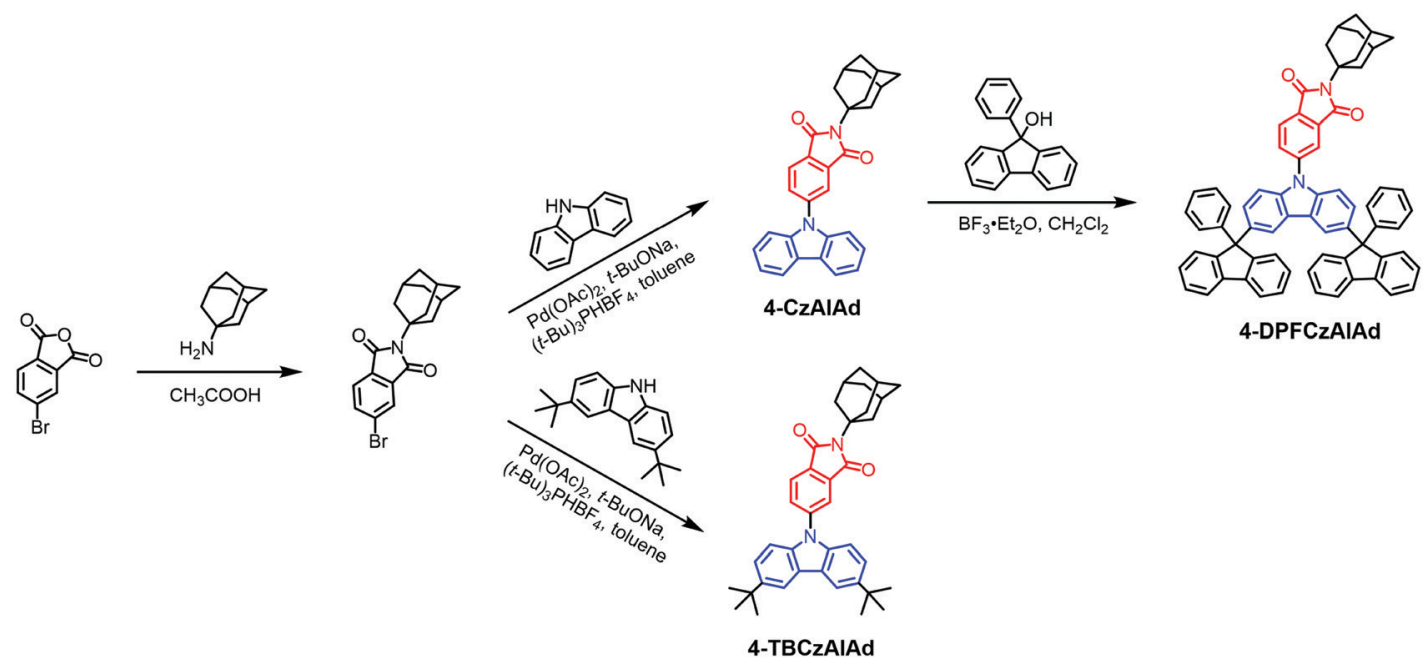

Scheme 1 Synthetic routes of 4-CzAIAd, 4-TBCzAIAd and 4-DPFCzAIAd. 
(a)

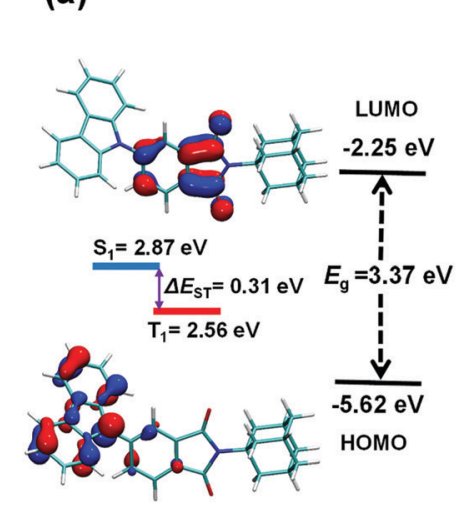

(b)

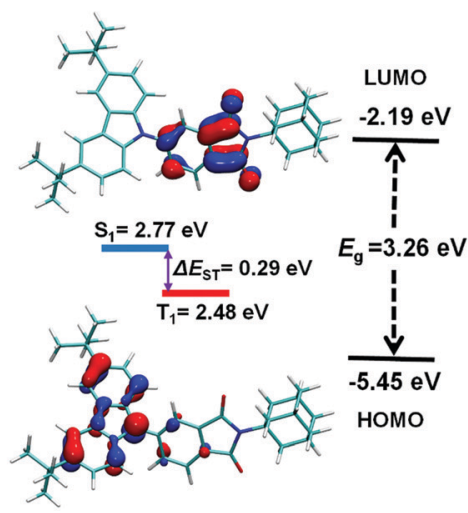

(c)

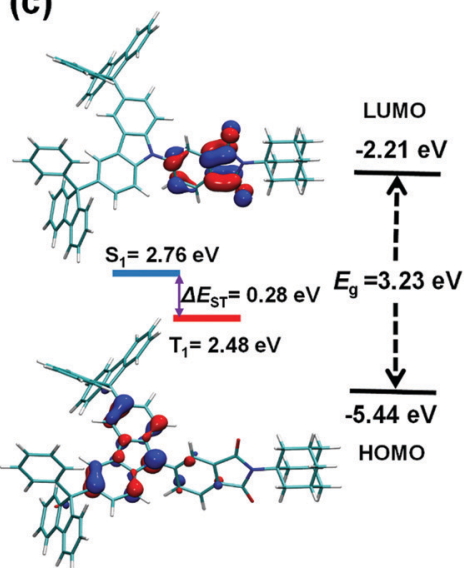

Fig. 1 Frontier molecular orbital distributions with calculated energy levels for (a) 4-CzAIAd, (b) 4-TBCzAIAd and (c) 4-DPFCzAIAd.

molecules, the HOMOs are predominantly located on the carbazolyl moiety, while the LUMOs are mainly distributed over the aromatic imide moiety. It can be found that the introduction of the tert-butyls and 9-phenylfluorenyl units barely affects the geometric distribution of these HOMOs and LUMOs. Meanwhile, there is a weak overlap between the HOMO and LUMO on the phenyl ring of the aromatic imide moiety, which is crucial for maintaining a high radiative decay rate. Upon introduction of tert-butyl and 9-phenyl-9-fluorenyl groups, 4-TBCzAIAd and 4-DPFCzAIAd, show a smaller energy gap than 4-CzAIAd, which can be attributed to the stronger electron donating ability of the new donors. Moreover, 4DPFCzAIAd achieves a smaller $\Delta E_{\mathrm{ST}}$ value than 4-CzAIAd and 4-TBCzAIAd, suggesting that a more efficient RISC process and TADF emission can be expected.

\section{Synthesis and structural characterization}

As depicted in Scheme 1, these TADF emitters 4-CzAIAd, 4TBCzAIAd and 4-DPFCzAIAd, can be synthesized in two or three steps from commercial 4-bromophthalic anhydride. The chemical structures of the intermediate and these emitters were confirmed by ${ }^{1} \mathrm{H}$ NMR, ${ }^{13} \mathrm{C}$ NMR and mass spectroscopy (Fig. S1-S4, ESI $\dagger$ ). High performance liquid chromatography (HPLC) was also performed to test the purity of these three emitters, assuring a purity of over 99\% (Fig. S5-S7, ESI $\dagger$ ). Furthermore, by slowly evaporating the mixture solvents of hexane and dichloromethane, all single crystals of these emitters were successfully obtained for single crystal X-ray diffraction measurement and the corresponding crystal data are collected in Table S1 (ESI $\dagger$ ). Fig. 2 demonstrates the intermolecular interactions of these compounds. For 4-CzAIAd, it can be found that two adjacent molecules form a head-tail dimer in an antiparallel configuration mainly through the interaction of $\mathrm{CH} \cdots \mathrm{O}(a: 2.498 \AA)$ and $\mathrm{CH} \cdots \pi(b: 2.791 \AA)$. As a result, its dimers are stacked into a regular layer structure, which can effectively provide a charge transfer pathway and enhance the mobility. Secondly, the carbazole donor and the acceptor unit aromatic imide (AI) present a large dihedral angle of $56^{\circ}$
(Fig. S8, ESI $\dagger$ ). The electron cloud density of the HOMO and LUMO can be effectively separated by such a twisted structure. Meanwhile, the solid-state fluorescence quenching caused by the intermolecular packing can be dramatically prevented. ${ }^{24}$ As for the single crystal of 4-TBCzAIAd, two adjacent molecules exist with several interaction forces including in $\mathrm{C}-\mathrm{H} \cdots \mathrm{H}$ ( $a: 2.212 \AA), \mathrm{C}-\mathrm{H} \cdots \mathrm{C}(b: 2.893 \AA), \mathrm{C}-\mathrm{O} \cdots \pi(c: 3.193 \AA)$ and $\mathrm{C}-\mathrm{H} \cdots \pi(d: 2.868 \AA$ and $e: 2.742 \AA)$. However, an interlocked layered structure was observed in the single crystal of 4-DPFCzAIAd, in which two adjacent molecules interact mainly through multiple $\mathrm{C}-\mathrm{H} \cdots \pi(a: 2.609 \AA, c: 2.889 \AA, d: 2.768 \AA$ and $e: 2.881 \AA)$ and $\mathrm{C}-\mathrm{H} \cdots \mathrm{H}(b: 2.396 \AA)$. In addition, there is a typical $\pi-\pi$ plane packing between the carbazole units of two neighboring 4-DPFCzAIAd molecules with a distance of $3.520 \AA$, which is much larger than those with effective $\pi-\pi$ intermolecular interactions $(\sim 3.4 \AA),{ }^{36}$ but may increase the lifetime of the triplet excitons. ${ }^{37}$

\section{Photophysical and TADF properties}

The UV-vis and PL spectra of these emitters in dilute toluene $\left(10^{-5} \mathrm{M}\right)$ were recorded to analyze their photophysical properties (Fig. 3). It can be seen that all these molecules exhibit a similar shape with peaks around $290-340 \mathrm{~nm}$, which can be attributed to the $\pi-\pi^{*}$ transitions. However, the weak absorption bands at the range of $340-440 \mathrm{~nm}$ are ascribed to the intramolecular charge transfer (ICT) transition from the carbazole unit to the aromatic imide unit. The featureless broad PL spectra demonstrate that their $\mathrm{S}_{1}$ states are regarded as ${ }^{1} \mathrm{CT}$ states. Upon introducing tert-butyl and 9-phenylfluorenyl units, the emission maxima bathochromically shift to $486 \mathrm{~nm}$ and $477 \mathrm{~nm}$ for 4-TBCzAIAd and 4-DPFCzAIAd, respectively, arising from their stronger electron donors and ICT interactions. To confirm the ICT properties of the excited state of these emitters for OLED applications, fluorescence spectra of the solutions were measured at room temperature using solvents with differing polarizability, as shown in Fig. S10 (ESI $\dagger$ ). They all exhibit distinct solvatochromic behavior $(\sim 100 \mathrm{~nm})$ as the solvent polarity increased from hexane to tetrahydrofuran, confirming. 
(a)

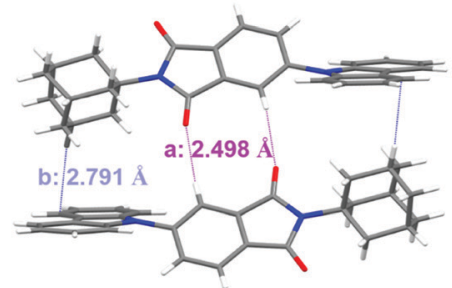

(c)

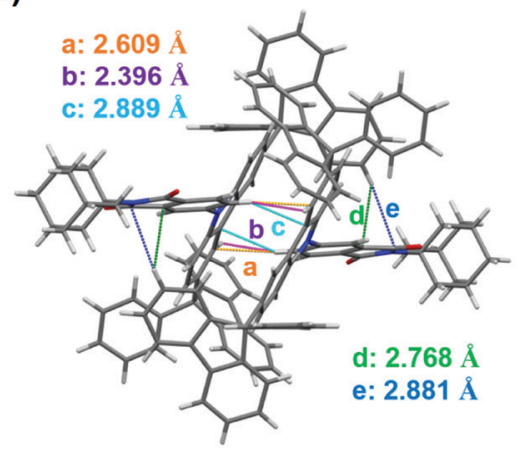

(b)

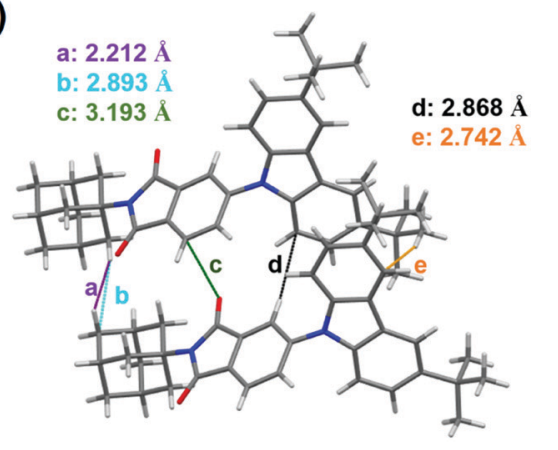

(d)

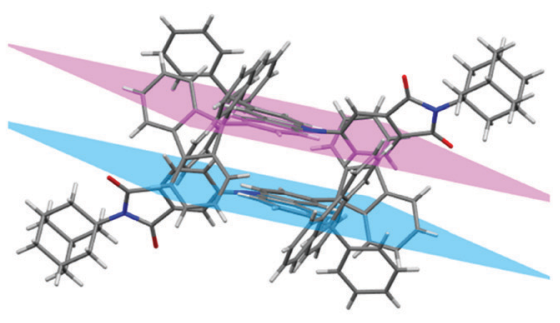

Fig. 2 Intermolecular interactions of (a) 4-CzAIAd, (b) 4-TBCzAIAd and (c) 4-DPFCzAIAd with the adjacent molecule. (d) $\pi-\pi$ intermolecular interactions for 4-DPFCzAIAd.

(a)

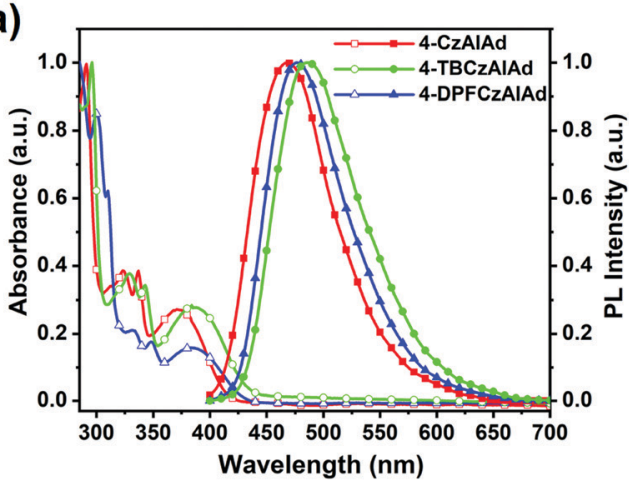

(c)

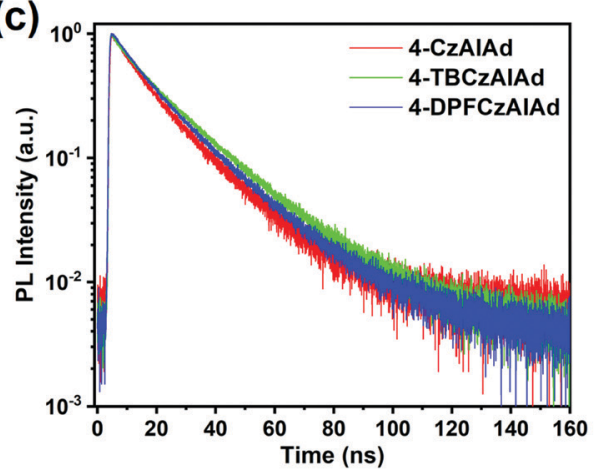

(b)

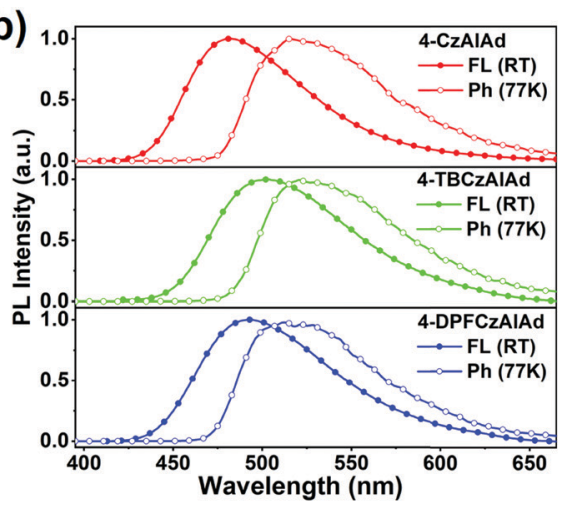

(d)

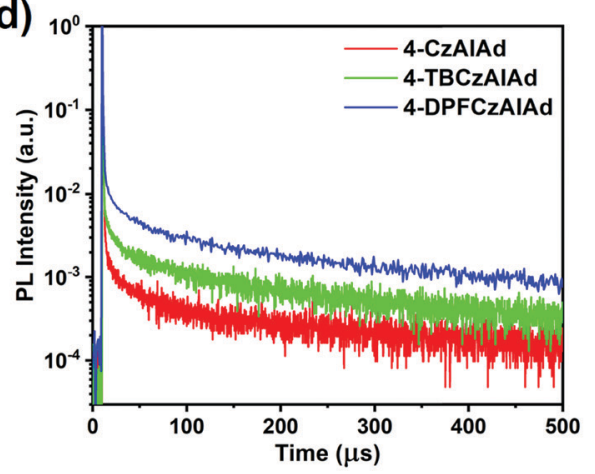

Fig. 3 (a) UV-vis absorption and PL spectra of the three emitters in toluene solution $\left(10^{-5} \mathrm{M}\right)$. (b) PL spectra and phosphorescence spectra of the three emitters in doped films. (c) The prompt decay curves and (d) delayed decay curves of the three emitters in doped films.

their strong ICT characteristics. The PL spectra of these emitterdoped bis[2-(diphenylphosphino)phenyl] ether oxide (DPEPO) films show emission peaks at 482, 502 and $492 \mathrm{~nm}$ for 4-CzAIAd, 4-TBCzAIAd and 4-DPFCzAIAd, respectively. The phosphorescence 
Table 1 Physical properties of 4-CzAIAd, 4-TBCzAIAd and 4-DPFCzAIAd

\begin{tabular}{llllllllllll}
\hline Emitter & $T_{\mathrm{d}} / T_{\mathrm{g}}{ }^{a}\left[{ }^{\circ} \mathrm{C}\right]$ & $\lambda_{\mathrm{ab}}{ }^{b}[\mathrm{~nm}]$ & $\lambda_{\mathrm{em}}{ }^{b}[\mathrm{~nm}]$ & $\mathrm{HOMO}^{c}[\mathrm{eV}]$ & $\mathrm{LUMO}^{c}[\mathrm{eV}]$ & $E_{\mathrm{g}}{ }^{d}[\mathrm{eV}]$ & $\tau_{\mathrm{p}}{ }^{e}[\mathrm{~ns}]$ & $\tau_{\mathrm{d}}{ }^{e}[\mu \mathrm{s}]$ & $E_{\mathrm{S}_{1}}{ }^{f}[\mathrm{eV}]$ & $E_{\mathrm{T}_{1}}{ }^{f}[\mathrm{eV}]$ & $\Delta E_{\mathrm{ST}}{ }^{f}[\mathrm{eV}]$ \\
\hline 4-CzAIAd & $349 /-$ & 371 & 468 & -5.68 & -2.68 & 3.00 & 16.2 & 25.3 & 2.84 & 2.60 & 0.24 \\
4-TBCzAIAd & $391-$ & 384 & 486 & -5.60 & -2.76 & 2.84 & 19.3 & 32.2 & 2.77 & 2.57 & 0.20 \\
4-DPFCzAIAd & $505 / 176$ & 383 & 477 & -5.73 & -2.84 & 2.89 & 17.5 & 33.0 & 2.83 & 2.64 & 0.19
\end{tabular}

${ }^{a} T_{\mathrm{d}}$ obtained from TGA measurement and $T_{\mathrm{g}}$ obtained from DSC measurement. ${ }^{b}$ Measured in toluene solution $\left(10^{-5} \mathrm{M}\right) .{ }^{c}$ The HOMO energy level is calculated from the oxidation potential and the LUMO energy level is calculated from $E_{\mathrm{HOMO}}$ and energy level gap $\left(E_{\mathrm{g}}\right){ }^{d} E_{\mathrm{g}}$ is derived from the onset of the absorption spectra. ${ }^{e}$ PL lifetimes of prompt decay component $\left(\tau_{\mathrm{p}}\right)$ and delayed decay component $\left(\tau_{\mathrm{d}}\right) \cdot{ }^{f} \mathrm{~S}_{1}$ and $\mathrm{T}_{1}$ energies were estimated from the edges of the fluorescence and phosphorescence spectra $\left(\Delta E_{\mathrm{ST}}=E_{\mathrm{S}_{1}}-E_{\mathrm{T}_{1}}\right)$.

spectra of the emitters were further measured in doped films at $77 \mathrm{~K}$, and the $\mathrm{S}_{1}$ and $\mathrm{T}_{1}$ energies were calculated from the onsets of the fluorescence and phosphorescence spectra, respectively. These corresponding data are collected in Table 1 . The $\Delta E_{\mathrm{ST}}$ values are determined to be $0.24,0.20$ and $0.19 \mathrm{eV}$ for 4-CzAIAd, 4-TBCzAIAd and 4-DPFCzAIAd, respectively. Moreover, these doped films also show a high photoluminescence quantum yield (PLQY) of $79.1 \%, 73.1 \%$ and $84.5 \%$ for 4-CzAIAd, 4-TBCzAIAd and 4-DPFCzAIAd in a nitrogen atmosphere at $300 \mathrm{~K}$, respectively.

The transient PL measurements at $300 \mathrm{~K}$ of these doped films were also conducted in order to further identify their TADF feature. It can be seen from Fig. $3 c$ and $d$ that all these emitters exhibited a delayed fluorescence component along with the prompt component, confirming the TADF properties of these materials. The transient decay times $\left(\tau_{\mathrm{p}}\right)$ were calculated to be 16.2, 19.3 and 17.5 ns for 4-CzAIAd, 4-TBCzAIAd and 4-DPFCzAIAd, respectively. The delayed components show a much longer lifetime ranging from $25.3 \mu$ s to $33.0 \mu$ s. Such long delayed lifetimes may be attributed to both the relatively large $\Delta E_{\mathrm{ST}}$ and the bulky adamantyl substituent that can effectively prevent the nonradiative relaxation. ${ }^{30,38}$ Furthermore, the PL intensity for the delayed component gradually increases with increasing temperature from $200 \mathrm{~K}$ to $300 \mathrm{~K}$ for these doped films (Fig. S11, ESI $\dagger$ ), which is an essential requirement for the TADF emitter because RISC will be accelerated by thermal energy.

\section{Thermal and electrochemical properties}

TGA and DSC were conducted under a nitrogen atmosphere to evaluate the thermal properties of these emitters. As shown in Fig. S12 (ESI $\dagger$ ) and Table 1, 4-CzAIAd exhibits a high decomposition temperature $\left(T_{\mathrm{d}}\right)$ of $349^{\circ} \mathrm{C}$. $T_{\mathrm{d}}$ is slightly increased to $391{ }^{\circ} \mathrm{C}$ after the carbazole donor is substituted by tert-butyl units, suggesting more excellent thermal stability for 4-TBCzAIAd. Upon replacing the tert-butyl with 9-phenylfluorenyl groups, the emitter 4-DPFCzAIAd shows the highest $T_{\mathrm{d}}$ of up to $505{ }^{\circ} \mathrm{C}$. No noticeable glass transition temperatures $\left(T_{\mathrm{g}}\right)$ were observed for both 4-CzAIAd and 4-TBCzAIAd emitters. However, 4-DPFCzAIAd exhibits a high $T_{\mathrm{g}}$ of up to $176^{\circ} \mathrm{C}$. Such excellent thermal properties of 4-DPFCzAIAd are favorable for the long-term stability of OLEDs. ${ }^{17}$

To further investigate the effect of tert-butyl and 9-phenyl-9fluorenyl substituents on the electrochemical properties of these TADF emitters, CV multi-sweep was performed in dichloromethane solutions. As shown in Fig. 4, all these emitters show

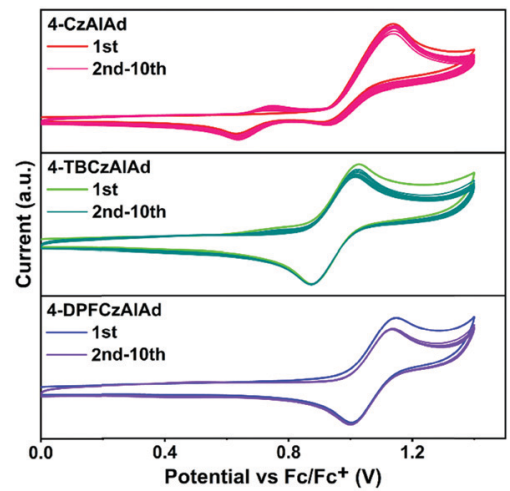

Fig. 4 Repeated cyclic voltammograms of 4-CzAIAd, 4-TBCzAIAd and 4-DPFCzAIAd in $\mathrm{CH}_{2} \mathrm{Cl}_{2}$ solutions.

reversible oxidation behaviors with the onset of oxidation potential. The HOMO energy levels are estimated according to these potential values and the LUMO energy levels can be calculated from the equation $E_{\mathrm{LUMO}}=E_{\mathrm{HOMO}}+E_{\mathrm{g}}$. The corresponding data are summarized in Table 1. One shoulder peak was observed at the second CV sweep and the current gradually increased during repeated cycling for the emitter 4-CzAIAd, which may be ascribed to the polymerization of the unsubstituted carbazole group. ${ }^{39,40}$ Upon substitution with tert-butyl groups, there was a slight change in the oxidation current under the same operation conditions. Although introducing two tertbutyl groups at the 3,6-positions of the carbazole moiety can effectively improve the electrochemical stability, ${ }^{41,42}$ this positive effect is significantly enhanced for 9-phenyl-9-fluorenyl substituents. Almost no change occurred from the second scan to the tenth for 4-DPFCzAIAd. The abovementioned results demonstrate that the substituents can notably increase the thermal and electrochemical stability and the 9-phenyl-9-fluorenyl group outperformances the tert-butyl group.

\section{Electroluminescence properties}

OLED devices using these emitters as dopants were fabricated to evaluate the influence of the substituents on the electroluminescence performance. The general device structure consisted of ITO/ $\mathrm{MoO}_{3}(2 \mathrm{~nm}) / \mathrm{TAPC}(20 \mathrm{~nm}) / \mathrm{mCP}(10 \mathrm{~nm}) / \mathrm{EML}$ $(25 \mathrm{~nm}) / \mathrm{TmPyPb}(40 \mathrm{~nm}) / \mathrm{LiF}(0.7 \mathrm{~nm}) / \mathrm{Al}(120 \mathrm{~nm})$. The device configurations, energy level diagrams and chemical structures of the materials are shown in Fig. 5. The doping concentration is optimized and determined to be $30 \mathrm{wt} \%$ for 4-DPFCzAIAd 
(a)

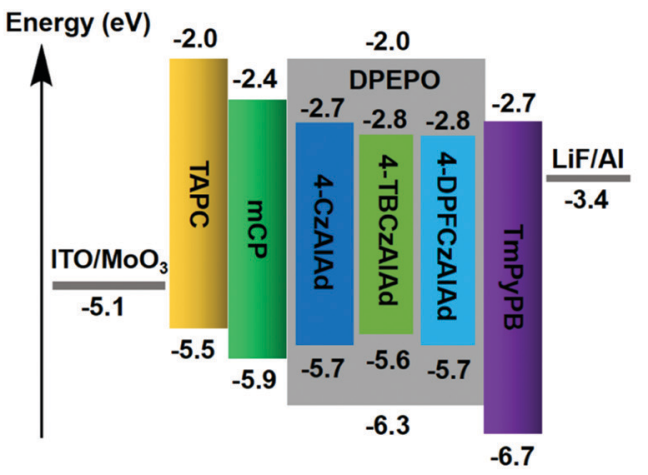

(b)

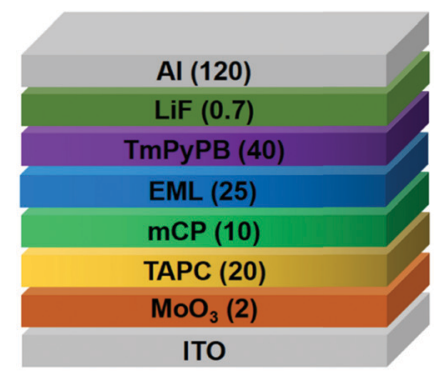

(c)
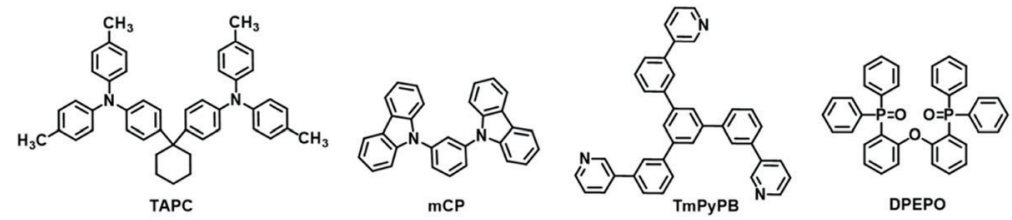

Fig. 5 (a) Energy level diagrams, (b) OLED device structure and (c) the chemical structure of the materials used in the TADF devices.

(Fig. S13 and Table S2, ESI†). One probable reason for the need of such a high concentration is that DPEPO cannot transport holes effectively and thus 4-DPFCzAIAd should perform this role. $^{43,44}$ The electroluminescence properties of these three fluorophores with the same doping concentration (30 wt\%) are illustrated in Fig. 6 and Fig. S14 (ESI $\dagger$ ), and their corresponding performance data are summarized in Table 2 . The OLED devices show bright-blue, green and sky-blue emission with a peak at $478 \mathrm{~nm}, 507 \mathrm{~nm}$ and $488 \mathrm{~nm}$ for 4-CzAIAd,
4-TBCzAIAd and 4-DPFCzAIAd, respectively. The turn-on voltage of device $\mathrm{C}(3.4 \mathrm{~V})$ is much lower than those of device $\mathrm{A}(6.5 \mathrm{~V})$ and device $\mathrm{B}(6.3 \mathrm{~V})$. This significant difference in turn-on voltage is probably caused by the difference in the holetransport properties of three emitters. For device A, a slight blue shift of EL emission and a small variation of CIE coordinates are observed when the driving voltage increases from $7 \mathrm{~V}$ to $11 \mathrm{~V}$ (Fig. S15a, ESI $\dagger$ ). Conversely, there is no obvious change in the EL spectra and CIE coordinates under the same (a)

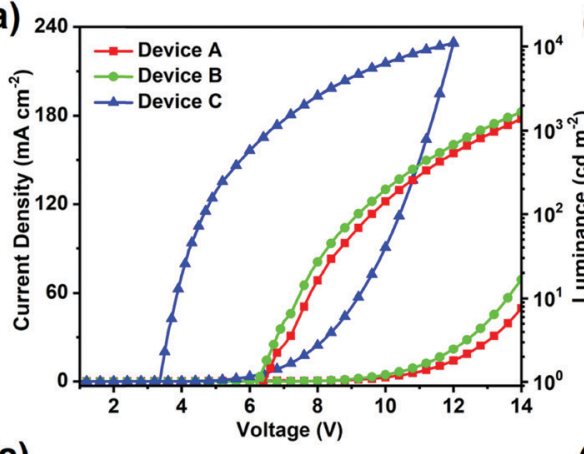

(c)

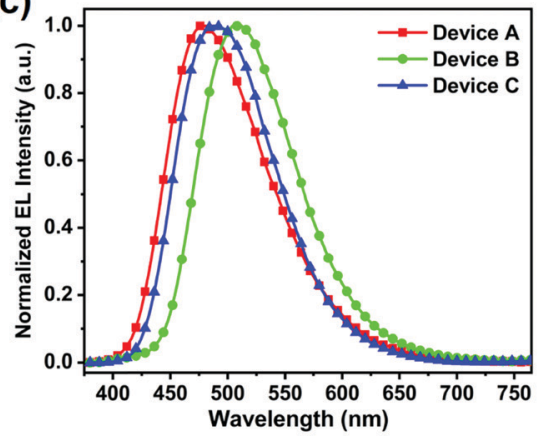

(b)

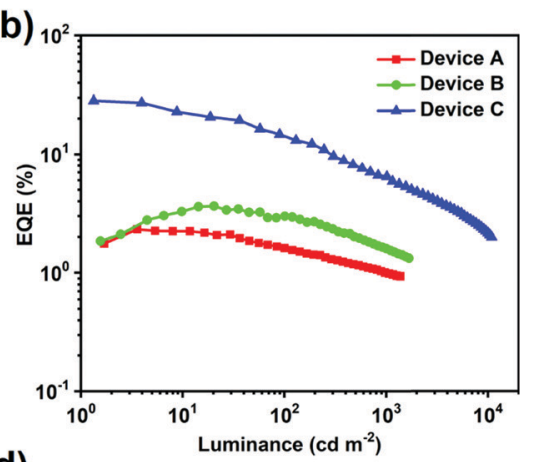

(d)

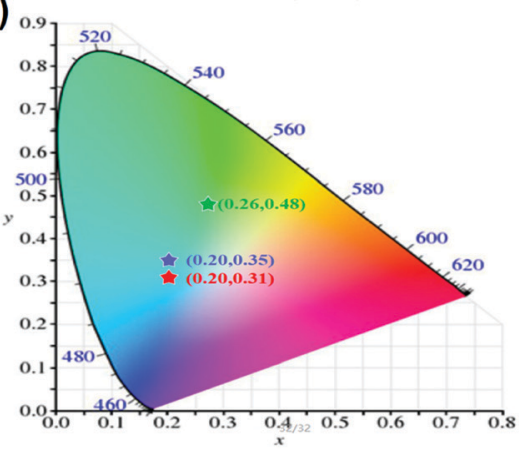

Fig. 6 EL performance of devices: (a) current density and luminance versus driving voltage, (b) EQE versus luminance, (c) EL spectra at $10 \mathrm{~V}$ and (d) CIE $(x, y)$ coordinates at a driving voltage of $8 \mathrm{~V}$. 
Table 2 Summary of EL data for devices A-C

\begin{tabular}{lllllllll}
\hline Device & Dopant & $V_{\mathrm{on}}{ }^{a}[\mathrm{~V}]$ & $\lambda_{\mathrm{EL}}{ }^{b}[\mathrm{~nm}]$ & $\mathrm{CIE}^{b}$ & $\mathrm{CE}^{c}\left[\mathrm{~cd} \mathrm{~A}^{-1}\right]$ & $\mathrm{PE}^{c}\left[\mathrm{~lm} \mathrm{~W}^{-1}\right]$ & $\mathrm{EQE}^{c}[\%]$ \\
\hline A & 4-CzAIAd & 6.5 & 478 & $(0.20,0.32)$ & $4.9 / 3.4 / 2.1$ & $2.2 / 1.1 / 0.5$ & $2.3 / 1.6 / 1.0$ \\
B & 4-TBCzAIAd & 6.3 & 507 & $(0.26,0.48)$ & $10.3 / 8.5 / 4.5$ & $4.6 / 2.9 / 1.1$ & $3.8 / 3.0 / 1.6$ & 34 \\
C & 4-DPFCzAIAd & 3.4 & 488 & $(0.20,0.36)$ & $67.1 / 34.1 / 15.2$ & $62.0 / 22.9 / 7.3$ & $28.2 / 14.2 / 6.4$ & 178
\end{tabular}

${ }^{a}$ Recorded at $1 \mathrm{~cd} \mathrm{~m}^{-2} \cdot{ }^{b}$ EL wavelength and CIE coordinates at a driving voltage of $8 \mathrm{~V} .{ }^{c}$ Maximum CE, PE and EQE and CE, PE, and EQE at 100 $\mathrm{cd} \mathrm{m}^{-2}$ and $1000 \mathrm{~cd} \mathrm{~m}^{-2}$, respectively. ${ }^{d}$ LT50 at an initial luminance of $500 \mathrm{~cd} \mathrm{~m}^{-2}$.

conditions for devices B and C (Fig. S15b and c, ESI $\dagger$ ), demonstrating a better balanced charge injection and transport in the emissive layer. $^{45}$

Furthermore, device A shows a maximum EQE of 2.3\%, current efficiency (CE) of $4.9 \mathrm{~cd} \mathrm{~A}^{-1}$ and power efficiency (PE) of $2.2 \mathrm{~lm} \mathrm{~W}^{-1}$ with a CIE color coordinate of $(0.20,0.32)$ (Fig. 6 and Fig. S15, ESI $\dagger$ ). As shown in Table 2, the better device performance of device B including higher EQE and CE can be explained by the smaller $\Delta E_{\mathrm{ST}}$ of 4-TBCzAIAd and its red-shifted emission compared to that of device $\mathrm{A}^{46}$ As expected, device C exhibits a superior EL performance with a maximum EQE of $28.2 \%$, CE of $67.1 \mathrm{~cd} \mathrm{~A}^{-1}$, PE of $62.0 \mathrm{~lm} \mathrm{~W}^{-1}$, and CIE color coordinates of $(0.20,0.36)$ compared to device B. One of the reasons for this apparent difference is probably the more efficient RISC process and well-matched hole-transport properties of EL devices upon replacing the tert-butyls with 9-phenyl-9fluorenyl units. In particular, for device $\mathrm{C}$, a relative high EQE of up to $6.4 \%$ and $2.2 \%$ can sustain at a luminance of $1000 \mathrm{~cd} \mathrm{~m}^{-2}$ and $10000 \mathrm{~cd} \mathrm{~m}^{-2}$ (Table S2, ESI $\dagger$ ). The significant roll-off of EQE is mainly attributed to the large $\Delta E_{\mathrm{ST}}$ and the long excited-state lifetimes of the emitters. ${ }^{47,48}$

Moreover, the operational lifespans of these OLEDs were also measured to explore the devices' stability at an initial luminance of $500 \mathrm{~cd} \mathrm{~m}^{-2}$ under a constant current (Table 2 and Fig. S15d, ESI $\uparrow$ ). DPEPO and TmPyPB are some of the most commonly used functional materials in OLEDs. Although these compounds are not suitable for the stability test, the main reason why we adopted these materials is that we aim to investigate the substituent effects on the performance of the OLED devices based on the novel TADF materials, including the EL efficiency and stability, under the routine conditions. Devices A, B and C display a LT50 of $16 \mathrm{~h}, 34 \mathrm{~h}$ and $178 \mathrm{~h}$, respectively. Compared with device $\mathrm{A}$, the lifetimes of the devices based on 4-TBCzAIAd and 4-DPFCzAIAd are increased by $c a$. 2 and 11 fold, respectively. The prolonged device lifetime by introducing the tert-butyl groups could be ascribed to the improved thermal and electrochemical stability and reduced exciton-polaron annihilation. ${ }^{17,32,45}$ The 9-phenyl-9-fluorenyl modified TADF emitter 4-DPFCzAIAd possesses more excellent thermal and electrochemical stability than 4-TBCzAIAd containing tert-butyl groups as aforementioned. Besides, the excitonpolaron annihilation tends to show a positive correlation with the intermolecular distance when steric bulks are introduced into the dopant molecules. In this context, compared with 4-TBCzAIAd, 4-DPFCzAIAd shows a larger intermolecular distance due to the larger steric hindrance of 9-phenyl-9-fluorenyl units relative to tertbutyl groups. As a result, device $\mathrm{C}$ displays a much longer operational lifespan than device B. To our knowledge, such a device is among the most efficient and stable blue TADF OLEDs with CIE coordinates of $(\leq 0.20, \leq 0.36)$.

\section{Conclusions}

In summary, three aromatic-imide-based TADF emitters are designed and synthesized. The substituent effect of tert-butyl and 9-phenyl-9-fluorenyl groups on their physicochemical properties and EL performance is systematically studied for OLED applications. It is found that 9-phenyl-9-fluorenyl groups are superior to tert-butyl units in increasing the thermal and electrochemical stability. Therefore, the 9-phenyl9-fluorenyl groups are more efficient to improve the EL performance and operational lifespan than the tert-butyl units. Upon introduction of tert-butyl units, the maximum EQE for 4-TBCzAIAd is slightly increased to $3.8 \%$ and LT50 is more than double with a value of $34 \mathrm{~h}$ at an initial brightness of $500 \mathrm{~cd} \mathrm{~m}^{-2}$. Promisingly, the sky blue device with a 9-phenyl9-fluorenyl modified emitter exhibits much better EL performance with a maximum EQE of up to $28.2 \%$ and a LT50 of $178 \mathrm{~h}$. To our knowledge, this work demonstrates one of the most efficient and stable blue TADF OLEDs with CIE coordinates of $(\leq 0.20, \leq 0.36)$. It is concluded that the 9-fluorenyl substitution strategy proposed here is a powerful approach to realize highly efficient and stable OLEDs without significantly compromising the color purity.

\section{Experimental section}

\section{Synthesis of 4-bromo- $N$-adamantyl phthalimide (4-BrAIAd)}

A mixture of 4-bromophthalic anhydride $(5.00 \mathrm{~g}, 30.12 \mathrm{mmol})$ and adamantanamine $(5.46 \mathrm{~g}, 36.14 \mathrm{mmol})$ in glacial acetic acid $(20 \mathrm{~mL})$ was refluxed for 12 hours. The reaction mixture was cooled to room temperature and then was slowly added to 100 $\mathrm{mL}$ of water, and a white precipitate was formed. The precipitate was filtered from the solution and washed with water. 4-BrAIAd (5.62 g, 52\%) was obtained as white powder without further purification, ${ }^{1} \mathrm{H}$ NMR $\left(400 \mathrm{MHz}, \mathrm{CDCl}_{3}\right): \delta 7.87(\mathrm{~d}, J=$ $1.6 \mathrm{~Hz}, 1 \mathrm{H}), 7.79(\mathrm{dd}, J=7.9,1.6 \mathrm{~Hz}, 1 \mathrm{H}), 7.61(\mathrm{~d}, J=7.9 \mathrm{~Hz}, 1 \mathrm{H})$, $2.48(\mathrm{~d}, J=2.6 \mathrm{~Hz}, 6 \mathrm{H}), 2.16(\mathrm{~s}, 3 \mathrm{H}), 1.82-1.67(\mathrm{~m}, 6 \mathrm{H}) .{ }^{13} \mathrm{C}$ NMR $\left(101 \mathrm{MHz}, \mathrm{CDCl}_{3}\right) \delta 167.91,167.29,135.61,132.58,129.48$, $127.39,124.85,122.96,59.76,39.11,39.11,35.11,28.75$. GC-MS (ESI): $m / z$ calcd for $\mathrm{C}_{18} \mathrm{H}_{18} \mathrm{BrNO}_{2}[\mathrm{M}]^{+}, 359.05$; found, 359.03 . 
Synthesis of 4-carbazolyl- $N$-adamantyl phthalimide (4-CzAIAd)

4-BrAIAd (1.00 g, $2.79 \mathrm{mmol})$, carbazole (0.70 g, $4.18 \mathrm{mmol})$, sodium tert-butoxide $(0.32 \mathrm{~g}, 3.34 \mathrm{mmol}),(t-\mathrm{Bu})_{3} \mathrm{PHBF}_{4}(0.06 \mathrm{~g}$, $0.17 \mathrm{mmol}$ ) and palladium(II) acetate $(0.01 \mathrm{~g}, 0.06 \mathrm{mmol})$ were dissolved in anhydrous toluene $(20 \mathrm{~mL})$ and stirred at $120{ }^{\circ} \mathrm{C}$ for 24 hours. After cooling to room temperature, the organic layer was extracted with dichloromethane $(3 \times 50 \mathrm{~mL})$, and then dried over $\mathrm{Na}_{2} \mathrm{SO}_{4}$, filtered and concentrated using a rotary evaporator. The residue was purified by flash column chromatography with dichloromethane and petroleum ether $(1: 3, \mathrm{v} / \mathrm{v})$ as eluents to give 4-CzAIAd $(0.74 \mathrm{~g}, 60 \%)$ as a faint yellow solid. ${ }^{1} \mathrm{H}$ NMR $\left(400 \mathrm{MHz}, \mathrm{CDCl}_{3}\right): \delta 8.15(\mathrm{~d}, J=7.8 \mathrm{~Hz}$, $2 \mathrm{H}$ ), 7.99 (d, $J=8.1 \mathrm{~Hz}, 2 \mathrm{H}), 7.89$ (dd, $J=7.9,1.5 \mathrm{~Hz}, 1 \mathrm{H}), 7.49-$ 7.40 (m, 4H), 7.37-7.31 (m, 2H), 2.60-2.53 (m, 6H), $2.21(\mathrm{~s}, 3 \mathrm{H})$ 1.85-1.73 (m, 6H). ${ }^{13} \mathrm{C} \mathrm{NMR}\left(101 \mathrm{MHz}, \mathrm{CDCl}_{3}\right): \delta 168.00,167.87$, $142.09,139.01,133.09,130.43,128.81,125.35,123.30,122.92$, 119.92, 119.53, 119.49, 108.51, 59.79, 39.22, 35.17, 28.80. HRMS (ESI): $m / z$ calcd for $\mathrm{C}_{30} \mathrm{H}_{27} \mathrm{~N}_{2} \mathrm{O}_{2}[\mathrm{M}+\mathrm{H}]^{+}$, 447.2073; found, 447.2064. Elemental analysis calcd (\%) for $\mathrm{C}_{30} \mathrm{H}_{26} \mathrm{~N}_{2} \mathrm{O}_{2}$ : C 80.69, H 5.87, N 6.27; found: C 79.57, H 6.67, N 5.80.

\section{Synthesis of 4-(3,6-di-tert-butyl-carbazolyl)- $N$-adamantyl phtha-} limide (4-TBCzAIAd)

In a similar way to 4-CzAIAd, 4-TBCzAIAd was obtained as a yellow solid (50\%). ${ }^{1} \mathrm{H}$ NMR (400 MHz, $\left.\mathrm{CDCl}_{3}\right): \delta 8.14(\mathrm{~d}, J=1.5$ $\mathrm{Hz}, 2 \mathrm{H}), 7.98$ (d, $J=1.3 \mathrm{~Hz}, 1 \mathrm{H}), 7.95$ (d, $J=7.9 \mathrm{~Hz}, 1 \mathrm{H}), 7.87$ (dd, $J=7.9,1.8 \mathrm{~Hz}, 1 \mathrm{H}), 7.48(\mathrm{dd}, J=8.7,1.9 \mathrm{~Hz}, 2 \mathrm{H}), 7.40$ (d, $J=8.6$ $\mathrm{Hz}, 2 \mathrm{H}), 2.56(\mathrm{~d}, J=2.3 \mathrm{~Hz}, 6 \mathrm{H}), 2.20(\mathrm{~s}, 3 \mathrm{H}), 1.86-1.70(\mathrm{~m}, 6 \mathrm{H})$, $1.47(\mathrm{~s}, 18 \mathrm{H}) .{ }^{13} \mathrm{C}$ NMR (101 MHz, $\left.\mathrm{CDCl}_{3}\right) \delta 168.10,167.96$, 143.00, 142.61, 137.31, 133.05, 129.77, 128.19, 123.19, 122.98, 118.87, 115.47, 108.03, 59.69, 39.22, 35.17, 33.75, 30.90, 28.80. HRMS (ESI): $m / z$ calcd for $\mathrm{C}_{38} \mathrm{H}_{43} \mathrm{~N}_{2} \mathrm{O}_{2}[\mathrm{M}+\mathrm{H}]^{+}, 559.3325$; found, 559.3318. Elemental analysis calcd (\%) for $\mathrm{C}_{38} \mathrm{H}_{42} \mathrm{~N}_{2} \mathrm{O}_{2}$ : C 81.68, H 7.58, N 5.01; found: C 79.47, H 7.67, N 4.70.

Synthesis of 4-(3,6-bis(9-phenyl-fluorenyl)-carbazolyl)- $N$-adamantyl phthalimide (4-DPFCzAIAd)

4-CzAIAd (100 mg, $0.22 \mathrm{mmol})$, 9-phenyl-9H-fluoren-9-ol (PFOH) (289 mg, $1.12 \mathrm{mmol}$ ) and boron trifluoride etherate (63 $\mathrm{mg}, 0.45 \mathrm{mmol}$ ) were dissolved in anhydrous dichloromethane $(200 \mathrm{~mL})$ and were stirred at room temperature under nitrogen for 4 hours. The organic layer was extracted with dichloromethane $(3 \times 50 \mathrm{~mL})$, and then dried over $\mathrm{Na}_{2} \mathrm{SO}_{4}$, filtered and concentrated using a rotary evaporator. The residue was purified by flash column chromatography with dichloromethane and petroleum ether $(1: 2, \mathrm{v} / \mathrm{v})$ as eluents to give 4-DPFCzAIAd (196 mg, 96\%) as a yellow solid. ${ }^{1} \mathrm{H}$ NMR $\left(400 \mathrm{MHz}, \mathrm{CDCl}_{3}\right): \delta 7.89(\mathrm{~d}, J=7.9 \mathrm{~Hz}, 2 \mathrm{H}), 7.81-7.80(\mathrm{~m}$, $2 \mathrm{H}), 7.78(\mathrm{~d}, J=7.5 \mathrm{~Hz}, 4 \mathrm{H}), 7.43(\mathrm{~d}, J=7.6 \mathrm{~Hz}, 4 \mathrm{H}), 7.38-7.33$ $(\mathrm{m}, 4 \mathrm{H}), 7.27$ (dd, $J=6.9,1.5 \mathrm{~Hz}, 4 \mathrm{H}), 7.23(\mathrm{~s}, 4 \mathrm{H}), 7.22(\mathrm{~s}, 10 \mathrm{H})$, $2.53(\mathrm{~d}, J=2.4 \mathrm{~Hz}, 6 \mathrm{H}), 2.18$ (s, 3H), 1.85-1.68 (m, 6H). ${ }^{13} \mathrm{C}$ NMR $\left(101 \mathrm{MHz}, \mathrm{CDCl}_{3}\right): \delta 167.96,167.75,150.56,145.40,142.01$, $139.00,138.18,137.57,133.02,130.03,128.62,127.22$, 127.03, 126.70, 126.42, 126.01, 125.62, 125.20, 123.19, 122.79, 119.17, 119.12, 118.90, 108.25, 64.47, 59.74, 39.17, 35.14, 28.78.
MALDI-TOF-MS: $m / z$ calcd for $\mathrm{C}_{68} \mathrm{H}_{50} \mathrm{~N}_{2} \mathrm{O}_{2}[\mathrm{M}]^{+}$, 926.39; found, 926.47. Elemental analysis calcd (\%) for $\mathrm{C}_{68} \mathrm{H}_{50} \mathrm{~N}_{2} \mathrm{O}_{2}$ : $\mathrm{C} 88.09$, H 5.44, N 3.02; found: C 87.11, H 6.04, N 2.68.

\section{Conflicts of interest}

There are no conflicts to declare.

\section{Acknowledgements}

This work was supported by the Natural Science Foundation of Jiangsu Province (No. BK20190090) and the National Natural Science Foundation of China (No. 21774061, 91833306, 61674081 and 61605090).

\section{Notes and references}

1 C. W. Tang and S. A. VanSlyke, Appl. Phys. Lett., 1987, 51, 913-915.

2 M. Zhu and C. Yang, Chem. Soc. Rev., 2013, 42, 4963-4976.

3 H. Uoyama, K. Goushi, K. Shizu, H. Nomura and C. Adachi, Nature, 2012, 492, 234-238.

4 D. Song, Y. Yu, L. Yue, D. Zhong, Y. Zhang, X. Yang, Y. Sun, G. Zhou and Z. Wu, J. Mater. Chem. C, 2019, 7, 11953-11963.

5 Y. Liu, C. Li, Z. Ren, S. Yan and M. R. Bryce, Nat. Rev. Mater., 2018, 3, 18020.

6 Y.-F. Xiao, J.-X. Chen, S. Li, W.-W. Tao, S. Tian, K. Wang, X. Cui, Z. Huang, X.-H. Zhang and C.-S. Lee, Chem. Sci., 2020, 11, 888-895.

7 D. Zhong, Y. Yu, D. Song, X. Yang, Y. Zhang, X. Chen, G. Zhou and Z. Wu, ACS Appl. Mater. Interfaces, 2019, 11, 27112-27124.

8 J. Li, W.-C. Chen, H. Liu, Z. Chen, D. Chai, C.-S. Lee and C. Yang, J. Mater. Chem. C, 2020, 8, 602-606.

9 Z. Yang, Z. Mao, Z. Xie, Y. Zhang, S. Liu, J. Zhao, J. Xu, Z. Chi and M. P. Aldred, Chem. Soc. Rev., 2017, 46, 915-1016.

10 D. Chai, X. Zeng, X. Su, C. Zhou, Y. Zou, C. Zhong, S. Gong and C. Yang, Chem. Commun., 2020, 56, 2308-2311.

11 D. H. Ahn, S. W. Kim, H. Lee, I. J. Ko, D. Karthik, J. Y. Lee and J. H. Kwon, Nat. Photonics, 2019, 13, 540-546.

12 T.-L. Wu, M.-J. Huang, C.-C. Lin, P.-Y. Huang, T.-Y. Chou, R.-W. Chen-Cheng, H.-W. Lin, R.-S. Liu and C.-H. Cheng, Nat. Photonics, 2018, 12, 235-240.

13 Y.-L. Zhang, Q. Ran, Q. Wang, Y. Liu, C. Hänisch, S. Reineke, J. Fan and L.-S. Liao, Adv. Mater., 2019, 31, 1902368.

14 X. Cai and S.-J. Su, Adv. Funct. Mater., 2018, 28, 1802558.

15 Q. Feng, S. Xie, K. Tan, X. Zheng, Z. Yu, L. Li, B. Liu, B. Li, M. Yu, Y. Yu, X. Zhang, L. Xie and W. Huang, ACS Appl. Polym. Mater., 2019, 1, 2441-2449.

16 T. T. Bui, F. Goubard, M. Ibrahim-ouali, D. Gigmes and F. Dumur, Appl. Sci., 2018, 8, 494.

17 D. Zhang, M. Cai, Y. Zhang, D. Zhang and L. Duan, Mater. Horiz., 2016, 3, 145-151. 
18 H. Noda, H. Nakanotani and C. Adachi, Sci. Adv., 2018, 4, eaao6910.

19 Q. Feng, K. Tan, X. Zheng, S. Xie, K. Xue, Y. Bo, H. Zhang, D. Lin, J. Rao, X. Xie, L. Xie, H. Cao, H. Zhang, Y. Wei and W. Huang, ChemPhotoChem, 2020, 4, 321-326.

20 A. D. Hendsbee, S. M. McAfee, J.-P. Sun, T. M. McCormick, I. G. Hill and G. C. Welch, J. Mater. Chem. C, 2015, 3, 8904-8915.

21 Q. Feng, X. Lu, G. Zhou and Z.-S. Wang, Phys. Chem. Chem. Phys., 2012, 14, 7993-7999.

22 X. Guo, F. S. Kim, S. A. Jenekhe and M. D. Watson, J. Am. Chem. Soc., 2009, 131, 7206-7207.

23 M. E. Jang, T. Yasuda, J. Lee, S. Y. Lee and C. Adachi, Chem. Lett., 2015, 44, 1248-1250.

24 M. Li, Y. Liu, R. Duan, X. Wei, Y. Yi, Y. Wang and C.-F. Chen, Angew. Chem., Int. Ed., 2017, 56, 8818-8822.

25 N. Venkatramaiah, G. D. Kumar, Y. Chandrasekaran, R. Ganduri and S. Patil, ACS Appl. Mater. Interfaces, 2018, 10, 3838-3847.

26 Y. Danyliv, D. Volyniuk, O. Bezvikonnyi, I. Hladka, K. Ivaniuk, I. Helzhynskyy, P. Stakhira, A. Tomkeviciene, L. Skhirtladze and J. V. Grazulevicius, Dyes Pigm., 2020, 172, 107833.

27 M. Chapran, R. Lytvyn, C. Begel, G. Wiosna-Salyga, J. Ulanski, M. Vasylieva, D. Volyniuk, P. Data and J. V. Grazulevicius, Dyes Pigm., 2019, 162, 872-882.

28 L. Li, T.-Q. Hu, C.-R. Yin, L.-H. Xie, Y. Yang, C. Wang, J.-Y. Lin, M.-D. Yi, S.-H. Ye and W. Huang, Polym. Chem., 2015, 6, 983-988.

29 C.-R. Yin, S.-H. Ye, J. Zhao, M.-D. Yi, L.-H. Xie, Z.-Q. Lin, Y.-Z. Chang, F. Liu, H. Xu, N.-E. Shi, Y. Qian and W. Huang, Macromolecules, 2011, 44, 4589-4595.

30 Y. Wada, S. Kubo and H. Kaji, Adv. Mater., 2018, 30, 1705641.

31 A. Kovalenko, C. Yumusak, P. Heinrichova, S. Stritesky, L. Fekete, M. Vala, M. Weiter, N. S. Sariciftci and J. Krajcovic, J. Mater. Chem. C, 2017, 5, 4716-4723.

32 C.-Y. Chan, M. Tanaka, H. Nakanotani and C. Adachi, Nat. Commun., 2018, 9, 5036.
33 X.-D. Zhu, Q.-S. Tian, Q. Zheng, X.-C. Tao, Y. Yuan, Y.-J. Yu, Y. Li, Z.-Q. Jiang and L.-S. Liao, Org. Electron., 2019, 68, 113-120.

34 Y.-F. Wang, H.-Y. Lu, C. Chen, M. Li and C.-F. Chen, Org. Electron., 2019, 70, 71-77.

35 D. H. Ahn, H. Lee, S. W. Kim, D. Karthik, J. Lee, H. Jeong, J. Y. Lee and J. H. Kwon, ACS Appl. Mater. Interfaces, 2019, 11, 14909-14916.

36 M. Tang, S. Zhu, Z. Liu, C. Jiang, Y. Wu, H. Li, B. Wang, E. Wang, J. Ma and C. Wang, Chem, 2018, 4, 2600-2614.

37 Y. Zhang, H. Ma, S. Wang, Z. Li, K. Ye, J. Zhang, Y. Liu, Q. Peng and Y. Wang, J. Phys. Chem. C, 2016, 120, 19759-19767.

38 G. H. Kim, R. Lampande, J. B. Im, J. M. Lee, J. Y. Lee and J. H. Kwon, Mater. Horiz., 2017, 4, 619-624.

39 E. Contal, C. M. Sougueh, S. Lakard, A. Et Taouil, C. Magnenet and B. Lakard, Front. Mater., 2019, 6, 131.

40 K. Karon and M. Lapkowski, J. Solid State Electrochem., 2015, 19, 2601-2610.

41 W. Jiang, L. Duan, J. Qiao, G. Dong, D. Zhang, L. Wang and Y. Qiu, J. Mater. Chem., 2011, 21, 4918-4926.

42 P. Rajamalli, V. Thangaraji, N. Senthilkumar, C.-C. Ren-Wu, H.-W. Lin and C.-H. Cheng, J. Mater. Chem. C, 2017, 5, 2919-2926.

43 P. Stachelek, J. S. Ward, P. L. dos Santos, A. Danos, M. Colella, N. Haase, S. J. Raynes, A. S. Batsanov, M. R. Bryce and A. P. Monkman, ACS Appl. Mater. Interfaces, 2019, 11, 27125-27133.

44 S. H. Han and J. Y. Lee, J. Mater. Chem. C, 2018, 6, 1504-1508. 45 Y. Zhang, D. Zhang, T. Tsuboi, Y. Qiu and L. Duan, Sci. China: Chem., 2019, 62, 393-402.

46 N. Jürgensen, A. Kretzschmar, S. Höfle, J. Freudenberg, U. H. F. Bunz and G. Hernandez-Sosa, Chem. Mater., 2017, 29, 9154-9161.

47 Q. Zhang, B. Li, S. Huang, H. Nomura, H. Tanaka and C. Adachi, Nat. Photonics, 2014, 8, 326-332.

48 C. Li, L. Duan, D. Zhang and Y. Qiu, ACS Appl. Mater. Interfaces, 2015, 7, 15154-15159. 